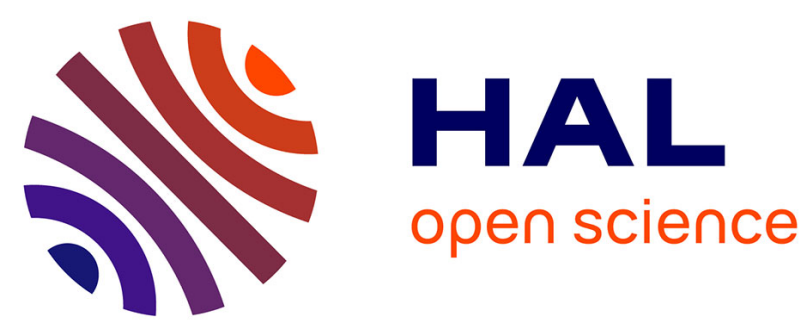

\title{
Manufacturing Execution Systems: The Next Level of Automated Control or of Shop-Floor Support?
}

\author{
S. Waschull, J. C. Wortmann, J. Bokhorst
}

\section{To cite this version:}

S. Waschull, J. C. Wortmann, J. Bokhorst. Manufacturing Execution Systems: The Next Level of Automated Control or of Shop-Floor Support?. IFIP International Conference on Advances in Production Management Systems (APMS), Aug 2018, Seoul, South Korea. pp.386-393, 10.1007/9783-319-99707-0_48. hal-02177868

\section{HAL Id: hal-02177868 \\ https://hal.inria.fr/hal-02177868}

Submitted on 9 Jul 2019

HAL is a multi-disciplinary open access archive for the deposit and dissemination of scientific research documents, whether they are published or not. The documents may come from teaching and research institutions in France or abroad, or from public or private research centers.
L'archive ouverte pluridisciplinaire HAL, est destinée au dépôt et à la diffusion de documents scientifiques de niveau recherche, publiés ou non, émanant des établissements d'enseignement et de recherche français ou étrangers, des laboratoires publics ou privés. 


\title{
Manufacturing Execution Systems: The Next Level of Automated Control or of Shop-Floor Support?
}

\author{
S. Waschull, J.C. Wortmann, J.A.C Bokhorst \\ University of Groningen, PO Box 800, 9700 AV Groningen, The Netherlands \\ s.waschullerug.nl
}

\begin{abstract}
Manufacturing Execution Systems (MES) are at the heart of industrial organizations' endeavors. While MES were traditionally positioned as an integration technology to bridge the shop-floor with higher level business systems, their current focus seems to be on the digitization of shop-floor activities for the collection, analysis and exchange of real-time information. Still, there remains dispute on the role of MES, specifically with respect to the functions they support in relation to other information systems in the automation pyramid, and their resulting interactions with humans. While MES are often positioned as the top layer of automated control of manufacturing processes, it is perceived by others as an integrated decision support system for the shop-floor. This study aims to shed light on the role of MES to either automate or to augment human tasks. Based on insights of a case study, we found that MES are neither automatic control nor solely decision support. MES' main role is the creation and maintenance of digital twins of products. This involves human interaction, which closely resembles work related to computer-aided engineering (CAE) systems. We expect that work in the sphere of MES will therefore increasingly resemble engineering work.
\end{abstract}

Keywords: manufacturing execution systems, automation pyramid, digital twin, shop-floor support

\section{Introduction}

The collection and analysis of large volumes of data generated throughout the product lifecycle is of growing importance for organizations. In line with that, more and more different forms of manufacturing execution systems (MES) have been implemented during the last decades [1] to deal with data in order to decrease cost, increase quality and meet efficiency requirements [2]. MES are also facilitators for implementing recent developments resulting from Industry 4.0 [3] and hence play a key role as an enabler of further innovation in manufacturing. Broadly speaking, MES focus on the digitization of shop-floor activities to monitor, document and report information on the transformation of raw materials into finished goods in an integrated manner, enabling the control and optimization of production processes in near real time [4-6] Whereas enterprise resource planning (ERP) systems focus on the horizontal integration across business functions, MES focus on the vertical integration of manufactur- 
ing processes with business processes by bridging enterprise information systems and the actual shop-floor [5]. This architectural view is commonly summarized in an automation pyramid that classifies and separates industrial systems [4]. MES then represent the middle layer in between ERP as a system of decision support, and the shopfloor mostly concerned with automated control [1]. However, this positioning leads to ambiguity on the role of MES and its interactions with other systems and with humans: Is MES a new layer of automated process control, or a system for business support?

The literature provides two perspectives. MES are sometimes positioned as systems to enable the vision of the automated lightless factory as promoted during the era of Computer Integrated Manufacturing (CIM). This perspective emphasizes the automation of all activities in the sphere of MES and shifts the focus for human tasks towards higher level business support [7]. Alternatively, MES are referred to as systems of decision support, similar to ERP, enabling empowered humans to take decentralized and well informed decisions on aspects of shop-floor control [8]. Several researchers already claimed that the automation pyramid will be transformed over the next years into a more decentralized and less rigid structure [9], but no further details were provided. Furthermore, it seems that MES functions are also supported by other information systems, leading to redundancy between these systems [10]. Despite a wide usage of MES, there are still unanswered questions such as: What is the exact role of MES? How do MES relate to (or how can they be differentiated from) other industrial systems in the automation pyramid? Are MES the next level of automated process control or of decision-support? What are implications for human tasks? These questions will be addressed in this research.

The next section provides an overview of the literature on MES and the role of MES as an integration layer. To further explore this empirically, Section 3 presents a case study at an aerospace company currently involved in the development of a MES. Based on the findings in Section 4, a discussion is provided in Section 5. Finally, Section 6 concludes.

\section{$2 \quad$ What is the Role of MES?}

The automation pyramid classifies industrial systems into distinct layers as can be seen in Figure $1[4,11]$. On the uppermost level, ERP takes on the role of the transactional backbone of all business processes and databases of a company [12].

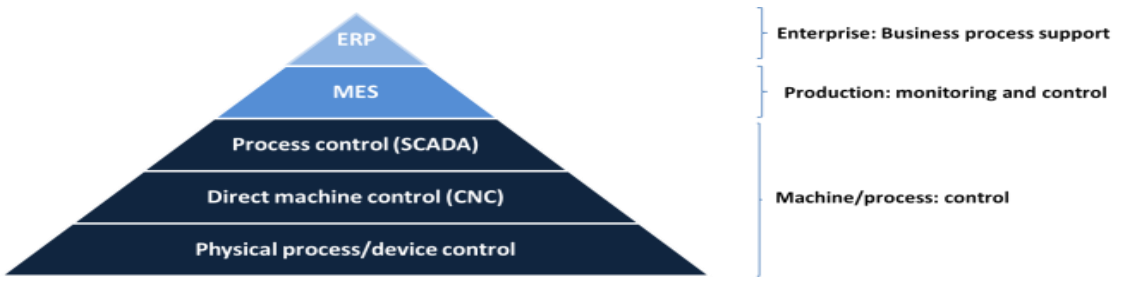

Fig. 1. Automation pyramid 
ERP supports the execution of business processes, such as order fulfillment or inventory control [13]. The bottom levels of the pyramid relate to automated control and are specifically hardware oriented, e.g. sensors, programmable logic controllers (PLC), and supervisory control and data acquisition (SCADA) systems. Control here concerns direct autonomous control actions with real-time sensors and actuators [14]. The middle level, i.e. where MES are positioned, is said to be bridging the gap between these upper and lower levels in the pyramid. The MESA standard defines several functions for MES, e.g. operations scheduling, dispatching, data collection, labour or quality management $[1,6,16]$. Despite standards, organizations are still struggling to define and demarcate the MES functionalities from other information systems available within the same layer (MES) and also across layers. This is because these information systems partly provide similar functions, e.g. document management (in PDM), inventory management (in ERP) or product tracking/dispatching (with control automation) [10]. In addition, even though there is a need to exchange data between manufacturing engineering and the shop-floor itself (e.g. the bill of material list, manufacturing instructions, control programs or possible nonconformances) [15], it is surprising to observe that industrial information systems supporting production innovation and their interactions with MES have been largely ignored in the automation pyramid. Computer-aided engineering (CAE) or product life cycle management (PLM) are such systems. Even though production definition management has been defined as a major aspect of MES in the ISA95 standard, it remains vague how and to what extent product innovation plays a role in aspects of MES, or how the design of product innovation systems is influenced by their usage in MES. To mention just one example, Engineering Change Management cannot be ignored in MES, but ISA95 does not seem to acknowledge this fact.

Finally, the interactions of MES with humans and their involvement in the control loop has not received much attention in the literature [16]. This is surprising considering that as Industry 4.0 takes shape, humans are required to be highly flexible and skilled to be able to work in a more complex and dynamic environment [17]. Hereof, two diverging perspectives on the role of MES and its interactions with humans can be described depending on how MES are approached in the pyramid. From the perspective of automated control, MES are described as a tool to achieve a fully automated and integrated manufacturing environment [7], as has been envisioned by the CIM movement [18]. This perspective views MES as the top layer of automated process control, extending control of the shop-floor components to control of all shopfloor control activities. In this view, MES and not humans eventually control the execution of manufacturing. From a different perspective, namely top-down, MES are presented as shop-floor decision support systems similar to ERP [8]. In this light, MES' main role is to collect, process and report information on various shop-floor activities in an integrated manner, to aid production monitoring and control shop-floor operations [6]. Workers can optimize their control decisions by providing accurate and timely information, and can react quickly [8]. Opposed to the light-free factory promoted in CIM, humans then remain essential in the activities located in the sphere of MES. 
In order to increase our understanding of the role of MES in the automation pyramid, we conducted an in-depth case study. The case study presented next focuses on a factory on its way to digitization while maintaining an important role for humans.

\section{Case Study}

This study is part of a larger in-depth longitudinal case study focusing on the impact of digitization on work. The case company is an aerospace company, which designs and manufactures discrete lightweight structures for the aerospace defense industry. The case provides the unique opportunity to study both the design and the implementation process of a MES. The first author of this paper has been involved as project team member for three years now and collected data through interviews, observations and archival documents.

\subsection{Rationale for MES Implementation}

The company operates under high variety, and is characterized by high quality and compliance requirements. In absence of a MES, the company currently works with different often isolated information systems on the shop-floor. The manufacturing planning and execution management is still highly manual and paper based. ERP and product lifecycle management (PLM) systems form the backbone of all manufacturing activities. Translating business and engineering requirements to the shop-floor and exchanging information between these two systems is, for a large part, accomplished by humans through an array of different paper based documents, databases and applications, e.g. weekly schedules and manufacturing instructions. Based on the current shop-floor control system, the following rationales for a MES were identified.

Shop-floor control. Manufacturing planning, scheduling and dispatching requires human expertise and human decision-making to synchronize high-level planning to existing capacity on the shop-floor (e.g. man-hours, machine capacity). Moreover, the case company has much difficulty to obtain accurate and real-time information on the position and status of production orders and production resources (e.g. machines, tooling) to facilitate optimal shop-floor control and to quickly react to changes.

Quality improvements \& information sharing. Currently, it is difficult to carry out many types of analysis for quality improvement activities and to learn from past decisions. First, registrations of as-built information (on the specific production process and product) are to a great degree still done on paper. It is hence difficult to conduct root-cause analyses and to connect quality issues in the line to the actual problems. Second, the company is working with islands of automation and disparate information systems (e.g. excel databases, functional information systems). Various functions (i.e. planning, engineering, dispatching) work independently and do not share information. Information is hence not transparent and shared to a limited extent.

Engineering data structure and manufacturing instructions. Engineering data (technical product specifications) are input for detailed manufacturing instructions created by the engineering department for each individual product. Currently, these instructions consist of multiple long PDF documents. They are non-standardized and 
instructions differ in syntax and structure. This results in a lot of manual labor when engineering changes need to be implemented and released. In addition, the use of multiple long instructions makes that operators either do not properly read the instructions, or spend a high share of their time looking for the right information. The following section describes the MES system architecture developed by the case company to overcome the stated problems, commencing with the digitization of manufacturing processes.

\subsection{MES Architecture at the Case Company}

The MES developed by the case company comprises the following computer applications: (1) a manufacturing process designer (MPD) to create and maintain manufacturing instructions based on engineering data, (2) a shop-floor manager (SFM) to control manufacturing activities, (3) a shop-floor viewer (SFV) to present manufacturing instructions to the operator and for digital registrations and (4) a registration manager (RM) to create a digital product dossier of as-built information.

Manufacturing Process Designer (MPD). The MPD is a system used by manufacturing engineering for production definition management, i.e. creating and managing manufacturing capabilities of processes and equipment. The MPD provides a digital library to create and maintain manufacturing instructions. Its data structure distinguishes manufacturing processes into standardized operations and processes (i.e. activities and tasks), equipment data (machines, materials) and customer specifications (authorizations required, quality items). The standardization of instructions and the resulting data model enables a more efficient implementation of engineering changes. These changes now only need to be made once and are valid for all related products and near real-time on the shop-floor. The system also keeps track of releases, resulting in different versions of instructions. Design engineering data (e.g. drawings) are maintained in the existing PLM system. Ultimately, the aim of the MPD is to move production engineers from thinking in preparation of long, heterogeneous verbose design documents to thinking in reusable, visual and modular process activities that are essential input for the detailed control and execution of processes.

Shop-Floor Manager (SFM). The SFM takes on a central function in the MES architecture. The SFM takes on functions of dispatching (e.g. resource allocation, clustering) and control by tracking and monitoring the status and progress of production orders. It is closely integrated with the MPD, which provides the "as planned" product data.

Shop-Floor Viewer (SFV). The SFV supports the workers on the shop-floor by providing manufacturing instructions developed in the MPD, i.e. the process flow, bill of material items and technical specifications. The operators are guided through the manufacturing process in a sequential manner, by following instructions and providing registrations when required (e.g. lot-numbers, product measurements, quality controls). The system automatically checks if these registrations are according to specifications; if workers are authorized and if a non-conformance is detected, the process stops and appropriate actions are taken. 
Registration Manager (RM). During the creation of the product, an RM captures all "as-built" data per production order in a digital file, resulting in the creation of a product digital twin. This digital twin includes three data categories, namely (1) general production order information (e.g. customer, quantity, production order) and release notes on instructions used, (2) planned production execution data (routings, processes, resources) and (3) as-built data of the manufacturing execution (actual activity and task flow with task times), BOM items and other customer specifications (quality items, certificates to perform and to release). To some extent, as-built data is dependent on various manual registrations provided through the SFV (e.g. approved control checks, reports, product measurements, environmental conditions).

\section{$4 \quad$ Findings}

MES are supporting humans in their job. MES are neither a top layer of automated control nor a purely decision support system. Through collecting and synthesizing data on the status of production orders, we find that MES' main function is the creation of digital twins of products that contain all relevant product related information on a low level of aggregation, i.e. operating parameters, environmental data. The product digital twin ensures that the product in use is monitored in real-time, relevant data is transparent, a historical record is built up, and data sources are integrated into one file. Other functions as outlined in the MESA standard are either executed manually or taken over by other information systems, and more or less integrated in the new MES architecture.

To build the product digital twin, input is required from several sources. One is input from sensor data and automatic controllers, others are detailed manufacturing instructions or other design documents. This shows that MES should be closely integrated with systems of product innovation. The execution of manufacturing is defined by engineers with the help of CAE to develop manufacturing instructions to support shop-floor workers in the production. Input for the CAE is delivered by the PLM, which means that PLM should be naturally linked with CAE in MES. In addition, insights from the MES must be reported back to CAE to enable the creation of improved instructions and process/product designs.

At the case company, humans receive an important role in the activities evolving around the creation and analysis of the product digital twin data. The digital product twin serves humans to make well-informed decisions regarding quality, shop-floor control and resource management. Humans even seem to take on a stronger role regarding the optimization of their processes due to the availability of digital product twin data and its data analysis possibilities. Data can be analyzed or potentially simulated to adjust and optimize scheduling and dispatching decisions, to connect quality issues to their root-cause, or to perform continuous improvement activities. Hence, human interaction with MES is abundant and humans are found to still play an essential role in all stages of the control loop at the case company, i.e. data collection, analysis and decision making. 


\section{Discussion}

In this paper, we aimed to clarify the role of MES in the automation pyramid. MES' main function is the collection and reporting of data and it centers on the creation of digital twins of products. Hence, we propose that MES should therefore not be positioned as a layer in between ERP and control systems in the automation pyramid, and that the hierarchical nature of industrial systems should be reconsidered, which is in line with general statements seen in earlier literature [9]. Systems of product innovation (CAE, PLM), execution management (MES) and business support (ERP) augment workers in industrial production and are clearly disparate from control systems that focus on automation aspects. We therefore adapt the top layer of the automation pyramid in Figure 2 to a comprehensive top layer. Here, the digital twin is central in the sphere of MES. It receives and reports information from and to other integrated industrial systems. Moreover, this study showed that MES are currently designed to support humans in their work. In the sphere of MES, humans will increasingly focus on activities evolving around the digital twin. Depending on the industry and the level of automation of companies, this level of involvement will vary. To some degree, the type of work in the sphere of the digital twin (e.g. registering, checking) will increasingly resemble engineering work. This means that remaining work in the sphere of MES could become more complex and might lead to higher skill requirements.

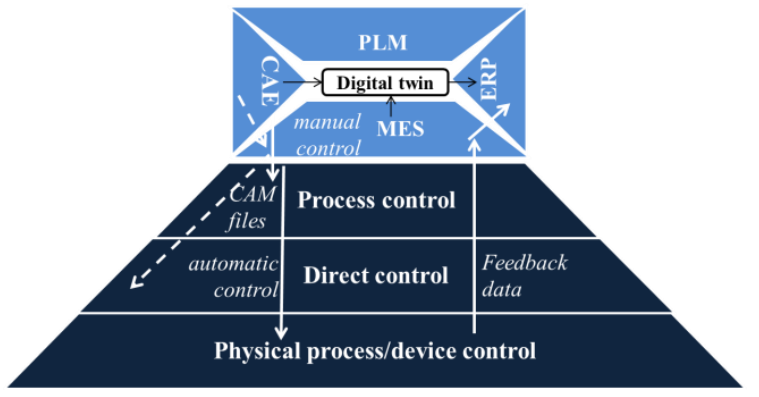

Fig. 2. Adjusted top layer of the automation pyramid

\section{Conclusion}

MES play a crucial role in the creation and maintenance of the digital twin of a product. MES should also be closely integrated with systems of product innovation to create the digital twin. MES is neither business support nor automatic control. Human interaction with MES is found to be essential in all stages of the control loop. Work in the sphere of MES will increasingly resemble work traditionally referred to as engineering work. In that sense, operators will then not only be involved in the production of the physical product, but also in the creation and maintenance of the digital twin. Future research should further elaborate and validate with more cases to obtain a more holistic picture. It would also be interesting to further elaborate which functions in the MESA standard are central to MES, and which are redundant. 


\section{References}

1. Harjunkoski, I., Nyström, R., Horch, A.: Integration of scheduling and control-Theory or practice? Comput. Chem. Eng. 33, 1909-1918 (2009).

2. Rondeau, P., Litteral, L.A.: The evolution of manufacturing planning and control systems: From reorder point to enterprise resource planning. Prod. Invent. Manag. J. 42, 1-7 (2001).

3. Arica, E., Powell, D.J.: Status and Future of Manufacturing Execution Systems. In: Proceedings of the 2017 IEEE IEEM. pp. 2000-2004 (2017).

4. ISA: ANSI/ISA 95: Enterprise-Control System Integration Part 3: Activity Models of Manufacturing Operations Management. (2005).

5. Romero, D., Vernadat, F.: Enterprise information systems state of the art: Past, present and future trends. Comput. Ind. 79, 3-13 (2016).

6. Ugarte, B.S. de, Artiba, A., Pellerin, R.: Manufacturing execution system - a literature review. Prod. Plan. Control. 20, 525-539 (2009).

7. Huang, C.: Distributed manufacturing execution systems : A workflow perspective. J. Intell. Manuf. 13, 485-497 (2002).

8. Naedele, M., Chen, H., Kazman, R., Cai, Y., Xiao, L., Silva, C.V.A.: Manufacturing execution systems: A vision for managing software development. J. Syst. Softw. 101, 59-68 (2015).

9. Monostori, L.: Cyber-physical production systems: Roots, expectations and R\&D challenges. Procedia CIRP. 17, 9-13 (2014).

10. Schmidt, A., Otto, B., Österle, H.: A Functional Reference Model for Manufacturing Execution Systems in the Automotive Industry. In: Wirtschaftsinformatik Proceedings. p. 89 (2011).

11. Williams, T.J.: The Purdue Enterprise Reference Architecture. Comput. Ind. 24, 141158 (1994).

12. Shehab, E.M., Sharp, M.W., Supramaniam, L., Spedding, T.A.: Enterprise resource planning: An integrative review. Bus. Process Manag. J. 10, 359-386 (2004).

13. Wortmann, J.: Evolution of ERP Systems. In: Strategic Management of the manufacturing value chain. pp. 11-23. Springer, Boston, MA (1998).

14. Shobrys, D.E., White, D.C.: Planning, scheduling and control systems: why cannot they work together. Comput. Chem. Eng. 26, 149-160 (2002).

15. Khedher, A.B.: Industrialization and manufacturing steps within the Global Product Lifecycle context. In: IFIP International Conference on Advances in Production Management Systems. Springer Berlin Heidelberg, Berlin (2009).

16. Pacaux-Lemoine, M.-P., Trentesaux, D., Rey, G.Z., Millot, P.: Designing intelligent manufacturing systems through Human-Machine Cooperation principles: A humancentered approach. Comput. Ind. Eng. 111, 581-595 (2017).

17. Gorecky, D., Schmitt, M., Loskyll, M., Zühlke, D.: Human-machine-interaction in the industry 4.0 era. Proc. - 2014 12th IEEE Int. Conf. Ind. Informatics, INDIN 2014. 289-294 (2014).

18. Cagliano, R., Spina, G.: Advanced manufacturing technologies and strategically flexible production. J. Oper. Manag. 169-190 (2000). 